\title{
Case management: an up-to-date review of literature and a proposal of a county utilization
}

\author{
Elisa Fabbri ${ }^{1}$, Maddalena De Maria ${ }^{2}$, Luca Bertolaccini ${ }^{3}$ \\ ${ }^{1}$ Healthcare Direction, Forlì Hospital, Ausl Romagna, Forlì, Italy; ${ }^{2}$ University of Rome Tor Vergata, Rome, Italy; ${ }^{3}$ Department of Thoracic Surgery, \\ AUSL Romagna Teaching Hospital, Ravenna, Italy \\ Contributions: (I) Conception and design: E Fabbri, M De Maria; (II) Administrative support: L Bertolaccini; (III) Provision of study materials or \\ patients: E Fabbri, M De Maria; (IV) Collection and assembly of data: All authors; (V) Data analysis and interpretation: All Authors; (VI) Manuscript \\ writing: All authors; (VII) Final approval of manuscript: All authors. \\ Correspondence to: Elisa Fabbri. Healthcare Direction, Forlì Hospital, Ausl Romagna, Forlì, Italy. Email: elisa.fabbri2@auslromagna.it.
}

\begin{abstract}
The current phase of development of health services is characterised by multiple changes that affect the organisational models of primary production lines (hospital, clinics, etc.) and the method of use by users. The clinical governance is a "strategy by which healthcare organisations are responsible for continuous improvement in the quality of services and achievement-maintaining high professional standards, stimulating the creation of an environment that fosters professional excellence". In this perspective of clinical governance, the role of the case manager with its clinical and managerial and financial skills becomes a key figure to ensure quality as a set of aspects of efficiency, effectiveness, safety, appropriateness, participation and equity. Case management fits perfectly in the context of assistance, to promote an increased quality of care, resulting in improved life, through coordination, integrating different professional contributions and ensuring continuity of care through all stages of treatment. In conclusion, preliminary results indicate that the increase of this organisation could be more functionally to reduce some team's gap.
\end{abstract}

Keywords: Nurse management; case manager; clinical governance; pathway to care

Submitted Jun 28, 2017. Accepted for publication Jul 13, 2017.

doi: $10.21037 /$ atm.2017.07.26

View this article at: http://dx.doi.org/10.21037/atm.2017.07.26

\section{Introduction}

The current phase of development of health services is characterised by multiple changes that affect the organisational models of primary production lines (hospital, clinics, etc.) and the method of use by users (1). The National Health Plan 1998-2000, plan Regional Health 2008-2010, the Decree "Regulations for The Rationalisation of The National Health Service" June 19, 1999, \#229 on the reorganisation of the NHS, frequently call concepts as appropriate effectiveness and efficiency. The fundamental element that unites the new national guidelines is the new thinking healthcare organisations, in which the quality is at the heart of the responsibilities of the institutions and becomes part of every professional.

The clinical governance is a "strategy by which healthcare organisations are responsible for continuous improvement in the quality of services and achievement-maintaining high professional standards, stimulating the creation of an environment that fosters professional excellence" (2).

In this perspective of clinical governance, the role of the case manager with its clinical and managerial and financial skills becomes a key figure to ensure quality as a set of aspects of efficiency, effectiveness, safety, appropriateness, participation and equity.

Case management fits perfectly in the context of assistance, to promote an increased quality of care, resulting in improved life, through coordination, integrating different professional contributions and ensuring continuity of care through all stages of treatment. Midwife, nurse and physical therapist, for their general and specific professional features, appear the most likely to engage in the role of case manager 
for assistance which requires a holistic and global vision (DRG n. 427/2009).

Depending on the context, organisational characteristics, needs and corporate philosophy, knowledge and experience of the staff members, assisted population, different terms are used to identify the model. The most used are: case management, managed care, care management, nursing care (or houses) management.

Case management involves the clinical administration of a target user population, from admission to discharge. Case management focuses on an episode of the disease and includes all the areas in which the customer receives assistance: is mainly used for patients or patient populations that require intensive levels of care (people in the terminal phase of life, elderly, frequent hospitalisations, high-risk socio-economic factors) (3).

\section{Case manager: role and functions}

Case management is a process that involves the coordination of services and the optimal use of available resources to the specific objective through a responsible professional core directly on the case. It is a professional with a specialised set of skills and practices that draw from the academic career and experience of different professional areas. Not having a narrow professional specificity, case/care manager may be the preserve of the various professionals (Table 1).

"The Case Manager is a professional who manages one or more cases entrusted to bim with a predetermined path, in a context of space and time defined" $(5,6)$.

The role of case manager is an operational function that, beyond its capacity and to its role in the diagnostic and therapeutic process, becomes concrete in support integration health responses around the person, and requires a prominent level of professionalism.

The purposes of the case manager are as follows:

* Plan, according to Director of Unit, nursing coordinator, the activities that guarantee the continuous assistance of the cancer patient, through the formulation of a shared path, taking charge, diversified according to clinical, assistance, functional and territorial needs;

* Participate in weekly multidisciplinary meetings;

* Create and share pathways of the takeover, diagnosis, treatment and departmental research;

* Contribute and improve the organisational and assistance conditions in conducting clinical studies.

The case manager depends on medical director and nursing coordinator and coordinate/collaborate with corporate planning and collaboration with nursing unit coordinators and corporate planning and collaboration with specific pathology group (7).

Since it is challenging to describe the functions of case managers, without referring to a real process of care, you can specify a set of general tasks that need to be completed. The stages of case management by the case manager are: assessment, planning, monitoring and evaluation of the outcome:

* Evaluation: unlike a medical diagnosis, the assessment must cover all aspects of the person involved in the diagnostic process. The evaluation should not be subjective but must provide objective information based on observation and the ability to use appropriate tools for a multidimensional assessment.

* Planning of the interventions: represents the central aspect of the function of case managers; in fact, the practitioner must seek the synchronisation of actions, arranging them in sequence according to criteria of suitability, and of course collaborate to avoid waste.

* Continuous monitoring: it is the function that allows the adaptation of the initial assessment, through the ongoing uncovering of diverse information. Continuous monitoring should establish conditions to determine if the effectiveness of treatment matches the actual practical efficiency (fundamental for physicians involved in the therapeutic process) The gradual reduction of the symptoms or their evolution, the appearance of side effects and their impact on overall functioning, is the primary object of observation. Monitoring also includes individual variables such as treatment satisfaction, acceptance of care and personal satisfaction.

* Evaluation of outcome: consists in the research carried out at the end of the diagnostic-therapeutic procedure, on the correlation between the expected objectives and outcomes achieved. Unresolved clinical problems must be reviewed, and this function is led, because of the diagnostic aspects, by the doctor; however, the case manager, together with the patient, should arrange to take care of remaining issues management to minimise their impact, to avoid relapses and to reduce any possibility of disability. 
Table 1 Job description of case manager (4)

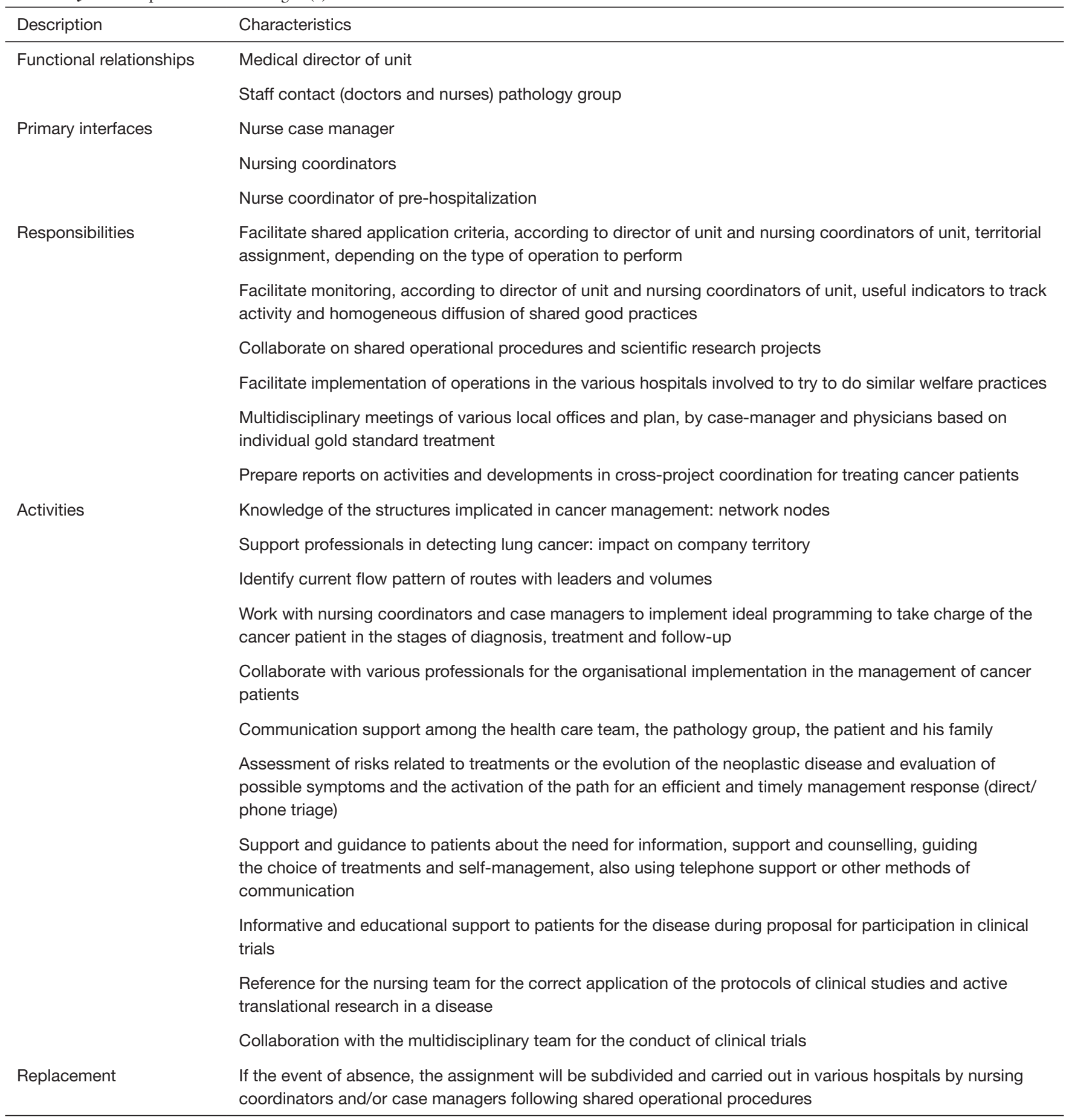


The case manager functions are:

(I) Facilitate communication with patients and families by promoting education;

(II) Identify patient care requirements;

(III) Support the development, implementation, monitoring service plan through interdisciplinary collaboration with the team and the patient;

(IV) Planner of assistance to minimise or eliminate errors in treatment;

(V) Pay attention to patient needs by encouraging the provision of effective and efficient individual assistance;

(VI) Analyse and synthesise data to define nursing diagnosis or interdisciplinary problems;

(VII) Direct the patient to the most appropriate resources and services;

(VIII) Facilitate access to facilities;

(IX) Monitor patient progress through the verification of the achievement of objectives.

There is no case of management model, but the different case management programs have defined this role, considering the methods that directly connect it to the organisational structure, to its mission, to financing systems and to the social and economic situation of the context in which they exercise. Therefore, there are three aspects of this role: financial, managerial and clinical (8).

\section{Clinical role}

It is the application of the nursing process, thus the evaluation of patients to identify their real and potential problems by trying to adapt the plan of assistance to the critical pathway that the case manager has previously developed with a multidisciplinary team and together with this team. It will identify any changes in the standards set forth and resolve variances. The case manager, an expert clinician, devotes part of his time to scientific evidence to promote an advanced type of practice and provide direct patient care type (9).

\section{Managerial role}

The case manager has the responsibility to facilitate and coordinate the care of patients while they are in charge. Together with the interdisciplinary team, he/she determines the objectives and the length of the hospital stay, manages and guides the assistance planning the treatment to meet the needs of patients and their families. The case manager must identify not more than three priority objectives and should determine when team members should be present, taking into consideration the peculiarities of the patient and his or her needs. He evaluates the quality of care to ensure the achievement of the objectives with an appropriate use of resources, and identify any opportunities for improvement of quality. The case manager should coordinate the extended care that begins with admission and continues to the follow-up at the patient's home after discharge. The release plan already starts at the time of taking charge. The case manager can personally follow the patient in clinical contexts or manage the patient's information in his possession so that every person who takes care of the patient will have access to this information about his health to assist him in the best way possible, in fact, the quality of care provided and the consequences of treatments and services will be assessed. The case manager also determines the need for team development and acts as teacher and tutor.

\section{Financial role}

In this function, one can monitor and collect information about the DRG to delete inappropriate care and resort to the most appropriate treatment. This role also has a significant role as an educator to both the health care team as well as to the patient and his family.

Therefore, the case manager must:

- Assess the training needs of the health care team and assist the nursing group in the development of protocols and guidelines;

- Provide necessary information to the patient and family of how to deal with the disease and to establish new behaviours that are needed;

* Have the capacity to communicate and negotiate with a variety of operators (10).

\section{Conclusions}

Technological development, scientific research, empowerment of the population and evidence-based practice have changed and will change; the clinical care organisational models, as well as the ever-increasing pressing need for health service efficiency and quality, will lead to a revolution in the management of such services as well as in health organisations. The mission of each professional is to fuse, at best, the ideal with the reality to offer each user/patient, the most appropriate treatment regarding timing and means. 


\section{Acknowledgements}

None.

\section{Footnote}

Conflicts of Interest: The authors have no conflicts of interest to declare.

\section{References}

1. Trinchero E. Case Management: approccio sistemico alla gestione del paziente. Mecosan 1999:33-45.

2. Fillion L, Cook S, Veillette AM, et al. Canadian professional navigation and person-centered approach: model, tools and competencies. Psycho-Oncol 2011;20:152-3.

3. Codice deontologico dell'infermiere. Available online: http://www.ipasvi.it/norme-e-codici/deontologia/ilcodice-deontologico.htm

4. Piano sociale e sanitario della Regione Emilia-Romagna. (delibera di Giunta regionale m. 284/2013). Available online: http://sociale.regione.emilia-romagna.it/entra-in-

Cite this article as: Fabbri E, De Maria M, Bertolaccini L. Case management: an up-to-date review of literature and a proposal of a county utilization. Ann Transl Med 2017;5(20):396. doi: $10.21037 /$ atm.2017.07.26 regione/piano-sociale-e-sanitario-della-regione-emiliaromagna

5. Mintzberg $\mathrm{H}$. The structuring of organizations: a synthesis of the research. Englewood Cliffs, NJ: PrenticeHall, 1979.

6. Molinari G. Management e leadership nelle organizzazioni sanitarie. Franco Angeli, 2005.

7. Bergamaschi M. Creazione del valore e organizzazione in sanità. McGraw-Hill Education, 2008.

8. Bruno P. Guida pratica alla direzione di struttura complessa in sanità. Gli strumenti del management sanitario come motore per il cambiamento organizzativo. Il Sole 24 Ore, 2009.

9. Progetto di costituzione del "Programma interaziendale comprehensive cancer care network" per l'attivazione della rete Oncoematologica della Romagna. 2015. Available online: https://amministrazionetrasparente.auslromagna.it/ documenti/E00/86/altro/Programma_CCCN.pdf

10. Gandini T. Le competenze e la valorizzazione del patrimonio umano in sanità. Una proposta metodologica per definire le competenze dell'infermiere con funzioni di coordinamento. Franco Angeli, 2011. 